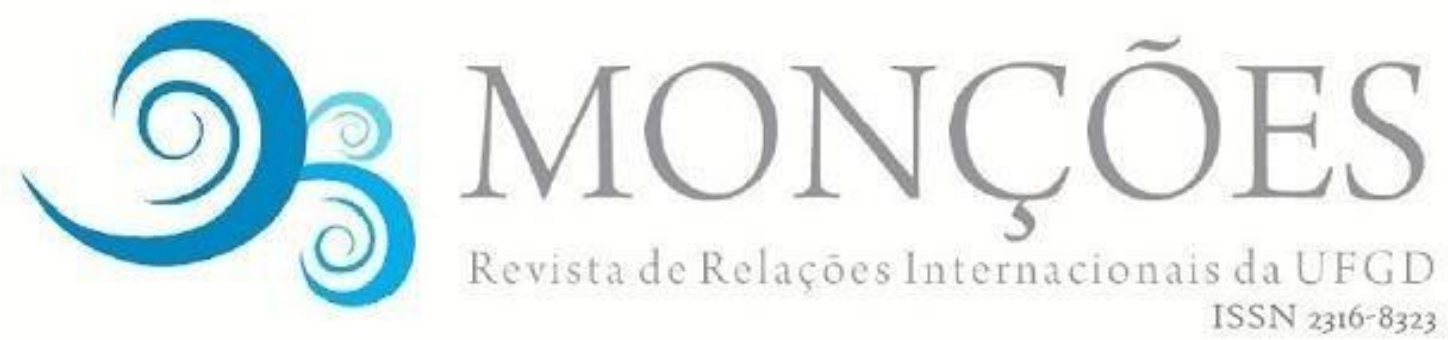

\title{
A INTERDISCIPLINARIDADE NOS ESTUDOS DAS RELAÇÕES INTERNACIONAIS: A CONTRIBUIÇÃO DA COMUNICAÇÃO SOCIAL AOS ESTUDOS SOBRE MÍDIA E POLÍTICA EXTERNA
}

PABLO FONTES

Doutorando em Relações Internacionais pela Pontifícia Universidade Católica do Rio de Janeiro (IRI/PUC-RIO).

CRISTINAREGO MONTEIRO DALUZ

Doutora em Comunicação e Cultura pela Escola de Comunicação da Universidade Federal do Rio de Janeiro (ECO/UFRJ).

DANIELLE COSTA DA SILVA

Pós-doutoranda pelo Programa de Pós-Graduação em Relações Internacionais da Universidade do Estado do Rio de Janeiro (PPGRI/UERJ).

ALANA CAMOÇA

Doutoranda em Economia Política Internacional pela Universidade Federal do Rio de Janeiro (PEPI/UFRJ).

TAÍSA REZENDE Mestra em Ciência Política pelo Instituto de Estudos Sociais e Políticos (IESP/UERJ).

RESUMO: O presente artigo propõe um exame sobre a interdisciplinaridade entre as áreas das Relações Internacionais e da Comunicação Social a partir da experiência docente da disciplina/curso de extensão "Política Externa, Mídia e Opinião Pública", na ECO-UFRJ, durante os anos de 2015 e 2016. Objetiva-se demonstrar a proximidade das duas áreas de conhecimento, o quanto elas se integram e sua importância enquanto campo de análise de estudo acadêmico.

PALAVRAS-CHAVE: Política Externa, Mídia, opinião pública, interdisciplinaridade, docência.

\section{INTERDISCIPLINARITY IN STUDIES OF INTERNATIONAL RELATIONS: THE CONTRIBUTION OF SOCIAL COMMUNICATION TO STUDIES ON MEDIA AND FOREIGN POLICY}

ABSTRACT: This article reflects about the interdisciplinary that exists between the fields of International Relations and Social Communication through the teaching experience of the discipline /extension course "Foreign Policy, Media and Public Opinion", at ECO-UFRJ, during the years 2015 and 2016. It aims to demonstrate the proximity of the two areas of knowledge, how they are integrated and their importance as a field of analysis of academic study.

KEYWORDS: Foreign Policy, Media, Public Opinion, Interdisciplinary, Teaching. 


\section{INTRODUÇÃO}

O campo de estudos das Relações Internacionais enquanto disciplina autônoma ainda é recente, principalmente quando pensamos nas universidades brasileiras. Existem muitos espaços a serem explorados, sobretudo no que diz respeito à interação com o papel global da mídia. Mais do que isso, a ausência dessa abordagem levanta questões estratégicas nos núcleos da ação política através da comunicação, seja ela jornalística ou na área do entretenimento. A existência dessa lacuna nos cursos de Relações Internacionais (Rl's) no Brasil compromete a compreensão de como, e quanto, a mídia tem influenciado e servido de instrumento de análise para os mais diversos debates internacionais. Foi a partir dessa lacuna que surgiu o interesse na criação do curso de extensão "Política Externa, Mídia e Opinião pública", realizado pela Escola de Comunicação Social da Universidade Federal do Rio de Janeiro (UFRJ) ${ }^{1}$.

A disciplina de Relações Internacionais surge pela primeira vez na Universidade do País de Gales, na Grã Bretanha, com a criação da cátedra Wodrow Wilson em 1919, logo após o fim da Primeira Guerra Mundial (19141918). As justificativas para tal proposta são evidentes, visto que os impactos da guerra no mundo e a dimensão internacional do conflito demonstraram a necessidade de um campo de estudo específico para a análise de problemas mundiais, onde pudessem ser abordados temas políticos, sociais, comerciais e bélicos, em conjunto. Assim, a área de Relações Internacionais surge com caráter e referências multi e interdisciplinares. Com a ascensão na contemporaneidade dos estudos de Análise de Política Externa (APE), surge também a preocupação de observar academicamente como diversos atores, além do Estado, atuam no campo da política externa.

Inserida nesse contexto, a mídia conquista cada vez mais espaço como ator político, exercendo pressão e funcionando como um Watch $\operatorname{Dog}^{2}$, ou quarto

\footnotetext{
${ }^{1}$ Posteriormente, o curso foi dis ponibilizado como disciplina eletiva durante os anos de 2015 e 2016.

2 Houve um tempo em que a imprensa era vista como demagoga, fanática, ou simplesmente feita por escritores de terceira categoria. Durante o século XIX, no ano de 1828, ainda sob o impacto da Revolução Francesa a expressão "Quarto Poder" era associada aos états (o termo francês para estado) às class es sociais da época (nobreza, clero, burgueses e o povo). No entanto, a partir de um novo enquadramento associado à democracia, com o princípio de poder controlando poder, a imprensa seria o quarto poder em relação aos outros três: o poder executivo, legislativo e o judiciário. Neste cenário descrito é que a imprensa, o
} 
poder, "vigiando" a agenda da política externa. Ela consegue, a partir do enquadramento de seus noticiários, produzir registros e reportagens que imprimem no cidadão brasileiro e internacional a construção de um imaginário que, em muitos aspectos, chega a não condizer com a realidade. Abre-se, desse nodo, um campo de estudos sobre mídia na área de Relações Internacionais. Seja por meio dos discursos (jornalismo diário, documentários, cinema), das imagens (fotografia), ou da análise das articulações institucionais como, por exemplo, no âmbito da diplomacia pública, onde a mídia funciona como instrumento de propaganda para vender uma imagem ou um discurso político entre os Estados e instituições mundiais. Compreendem-se então os meios de comunicação de massa como possíveis influenciadores no processo de significação do mundo frente ao público, no papel de construtor social da realidade, ao lado de outros tantos processos de interação e edificação social. Com isso, a mídia pode ser identificada como um dos fatores de grande influência no estímulo ao debate público, favorável ou não a alguns discursos, incidindo nos comportamentos sociais, estruturando visões de mundo e gerando percepções de impacto na opinião pública ${ }^{3}$.

Logo, através de um estudo de todos esses elementos e pontos, o artigo objetiva: demonstrar a importância dos estudos de análise de política externa compreendendo-a como política pública e entendendo a mídia como um ator formador de opinião pública; entender o desenvolvimento do curso de relações internacionais no Brasil, particularmente, da subárea Análise de Política Externa (APE), pontuando uma breve análise histórica do campo e a carência que existe da participação da mídia como elemento, não apenas, de construção de narrativas, de conteúdo de discurso, mas também como formador da opinião pública; e exemplificar a importância da interdisciplinaridade entre as Relações Internacionais e a Comunicação Social a partir da observação participante do Laboratório de Extensão universitária "Política Externa, Mídia e Opinião Pública", da Escola de Comunicação da Universidade Federal do Rio de Janeiro

\footnotetext{
jornalismo em si, necessitou de uma legitimidade para tranquilizar os receios e ao mesmo tempo justificar o seu crescente lugar na sociedade dando cobertura a um negócio rentável (Traquina, 2005, p.45-47).

${ }^{3}$ Ainda que essa opinião pública não se molde exclusivamente pela ação da mídia, também se admite aqui que fatores como contextos social, econômico e político sejam ambientes que contribuem na moldura que formará a opinião pública.
} 
(ECO/UFRJ). Os dois primeiros tópicos a serem trabalhados, o entendimento da política externa como sendo política pública, onde a mídia é entendida como sendo um importante ator, e o levantamento histórico da APE, centrado no tópico da mídia como objeto de pesquisa, são etapas secundárias, porém necessárias, para explicar a interdisciplinaridade existente entre as Relações Internacionais e a Comunicação Social e as contribuições dos estudos midiáticos no campo da APE, principal objetivo do presente artigo e o princípio motivador da experiência docente aqui relatada.

\section{POLÍTICA EXTERNA É POLÍTICA PÚBLICA: A MÍDIA COMO ATOR}

Para entender a Mídia como ator nas relações internacionais, o estudo da Análise de Política Externa (APE) é fundamental, visto que a APE pode ser caracterizada como sendo o estudo dos tomadores de decisão, que agem individualmente ou em grupo, consistindo em uma análise aberta, conceitual, interdisciplinar que procura ir além das fronteiras entre o doméstico e o externo. Devido às diversas mudanças globais, nos campos social, econômico e político, dentre os impactos resultantes sobre as políticas doméstica e externa dos países estão o entrelaçamento entre o nível doméstico e o internacional e a questão do pluralismo da agência ${ }^{4}$ (Hill, 2003). Por meio da compreensão de que o comportamento externo de um país é determinado por fatores e atores domésticos, torna-se vital analisar o impacto de tais atores domésticos, estatais e não estatais (por exemplo, da mídia), na formulação da política externa de um Estado, se contrapondo à visão realista estadocêntrica ${ }^{5}$ ainda predominante na política externa e nas relações internacionais. Milner (1997) argumenta que a política doméstica e as relações internacionais estão intrinsecamente relacionadas: a posição internacional de um país exerce um impacto importante nos seus assuntos de política interna, como na sua agenda econômica, assim

4Por agência deve-se entender a capacidade de agir; aqueles dotados de agência são os agentes, entidades capazes de decisões e ações em qualquer contexto, podendo ser individuais ou coletivos.

5Fundamentada na noção do Estado como sendo o ator unitário das relações internacionais e da política externa, a perspectiva realista alega a separação entre o campo doméstico e internacional. Segundo Waltz (1996), a função da política externa seria buscar, utilizando a teoria da política internacional, como Estados similares atuam de forma diferente, tendo a preocupação de observar os padrões de comportamento para explicar o quê causa tais padrões. 
também o inverso se faz valer, ou seja, a situação interna dos Estados pode moldar seu comportamento nas relações exteriores.

A inter-relação entre o nível doméstico e o nível externo introduz um tópico essencial à nossa reflexão: a pluralização dos agentes, pois o foco da análise da política externa passou a ir além dos Estados, considerando também outros atores tais como os tomadores de decisão, legisladores e demais grupos domésticos e internacionais como sendo agentes da política externa. Essa questão conta com o emblemático estudo comparativo de Margaret G. Hermann e Charles F. Hermann (1989) sobre os diferentes setores de governo ${ }^{6}$ que influenciam na formulação da política externa, o qual propõe as possíveis condições que afetariam a forma como a decisão é tomada no âmbito da política externa e, por fim, assinala a dinamicidade desse processo, visto que a unidade decisória pode variar de acordo com a natureza do problema tratado. Por sua vez, Hill (2003), considerando a emergência de novos atores na política externa, observa que os atores políticos envolvidos são todos indivíduos humanos dotados (em graus diferentes) de agência, e, portanto, responsáveis pela tomada de decisão (decision making) e pela implementação das políticas. Transpondo a reflexão da pluralidade de atores para o âmbito digital, Castells (2013), analisando o surgimento dos movimentos sociais na internet, em relação às repercussões de postagens nas plataformas digitais, crê que será necessário reinventar a política, já que ela não está suprindo as necessidades básicas da população, mas servindo a ela mesma. Dessa forma, ascende, na prática e nas reflexões teóricas, a de que diversos atores internacionais, transnacionais e domésticos são capazes de representar interesses na escolha e implementação de decisões da política externa.

Nesse quadro, surgem subáreas de conhecimento que contribuem com um aprofundamento do estudo a respeito da dimensão política da internet, como por exemplo, as áreas vinculadas à abordagem antropológica. Ainda pouco absorvido pelas Rl's, o olhar antropológico traz elementos que auxiliam a evitar

6 Os autores apontam três unidades de decisão possíveis de serem aplicadas, dependendo do problema em questão: o líder predominante (um indivíduo sozinho com o poder de escolha), o grupo independente (conjunto de indivíduos de um determinado grupo) e múltiplos atores autônomos (presença de múltiplos atores, individuais e coletivos). 
um dos possíveis equívocos gerados pela segmentação de áreas de conhecimento depois da chegada da grande rede na sociedade contemporânea:

a crença de que o virtual e o real estão se fundindo em um único domínio (Boelsltroff, 2011). A Antropologia Digital contribui para uma visão mais clara da natureza da inserção cultural de fluxos e bloqueios de circulação de dados, opiniões e ações conectadas. Aborda, sob o ângulo de interesse das Rl's, desde aspectos de e-government (o uso das tecnologias de informação para prestação de serviços públicos), e do m-government (uso do mobile e da inserção da participação das redes sociais em mobilizações que ganham representatividade na Esfera Pública - tratada aqui menos como o conceito relacionado por Habermas a uma fase da história europeia e mais como uma instância ampla de conexão global), até os importantes processos políticos e suas dimensões digitais. Como diz John Postill (2012), "the devil is in the technopolitical details"?.

\begin{abstract}
Uma área negligenciada de grande potencial para futuras pesquisas antropológicas é o Estudo de virais políticos - conteúdos digitais de natureza política que se propagam como epidemia através de plataformas on-line, dispositivos móveis e configurações de face-aface. O estudo de Política Digital e Engajamento Político (...) foi até agora deixado em grande parte para profissionais de marketing e novos gurus da mídia. E, no entanto, virais são um pilar dos ambientes de mídia contemporânea (Postill, 2012; Wasik 2009; Heather; Miller, 2012).
\end{abstract}

Assim sendo, enquanto algumas interpretações clássicas de Política Externa $^{8}$ trazem somente a figura do Estado como ator unitário nas decisões internacionais, existem outras interpretações que entendem a política externa como sendo uma política construída por meio de um conjunto fundamental de contribuições e influências de atores diversos. Segundo Milani e Pinheiro (2013):

Empresas, organizações não governamentais, mídia, movimentos sociais, igrejas, organismos públicos municipais ou estaduais, por exemplo, passaram a atuar internacionalmente de maneira mais orgânica e articulada, agindo em muitas ocasiões à revelia do próprio Estado, em nome de interesses privados ou ainda na defesa de causas

\footnotetext{
7 “O diabo está nos detalhes tecnopolíticos". Tradução nossa.

${ }^{8}$ Compreendemos que existe uma literatura anterior, ao conceito de Política Externa como Política Pública, que não aceita e/ou concorda com esta visão conceitual, aplicada à realidade brasileira. No entanto, adotamos esta literatura tendo em vista as modificações que ocorreram, sobretudo, nos últimos mandatos presidenciais que possibilitaram que novas agendas e atores tivessem maior participação e atuação na Política Externa.
} 
políticas das mais diversas. Disso tudo resulta o reconhecimento da inegável conexão entre problemas internacionais e temas domésticos. As crises financeiras globais afetam o cotidiano dos cidadãos, a difusão midiática do aquecimento planetário influencia comportamentos no âmbito local, a defesa dos direitos humanos em países distantes mobiliza pessoas de inúmeras nacionalidades (Milani e Pinheiro, 2013, p.5).

Quando a política externa segue a lógica de ser apenas uma política de Estado, assumindo uma interpretação mais ortodoxa do texto constitucional, ela fortalece o insulamento burocrático, no caso brasileiro, do Ministério das Relações Exteriores (MRE). Todavia, quando a política externa é tratada como política pública, permite abrir portas, realizar diálogos. Sendo então uma política pública, a política externa está sensível ao processo de politização ${ }^{9}$, a qual é própria da democracia. Portanto, a presença de vários e distintos atores, cujos poderes de agência diferem em termos de acesso às informações, nível de participação na formulação da política e capacidade legal ou constitucional de agir, colabora para tornar a política externa mais plural e democrática, agregando outros valores, ideias, interesses e demandas.

Reconhece-se, então, a política externa brasileira como política pública ao trazê-la para o terreno da politics por meio do reconhecimento de que sua formulação e implementação estão inseridas na dinâmica das escolhas de governo e da crescente politização de sua agenda, devido não só à presença de diversos atores não estatais, como da ruptura com o insulamento burocrático do MRE. De fato, autores como Milani e Pinheiro (2013) compreendem, através dos seus estudos, uma nova configuração na política externa brasileira a partir de parâmetros que possam trazer novas formas de atuação de atores presentes, buscando mecanismos de maior participação e interação. Assim sendo, é necessário abrir a caixa preta, ou seja, fazer com que a política externa deixe de se apresentar como uma área isolada das demais, percebendo que fatores domésticos influenciam e refletem na forma de conduzir uma determinadaação. Isto é, desvincular a política externa para fins Realista ou Neorealista.

\footnotetext{
${ }^{9}$ Entende-se por politização a intensificação do debate de ideias, valores e interesses sobre escolhas políticas, como também de disputas inter e intraburocráticas, e debates entre atores sociais distintos quanto à melhor forma de contemplar suas demandas, o que insere a política externa na arena do embate político (Milani; Pinheiro 2013, p. 29-30).
} 
É nesse sentido que o MRE, num mundo cada vez mais conectado e globalizado, utiliza ferramentas como Twitter e Facebook como forma de diálogo e maior interação com a sociedade civil diante do tema da política externa brasileira. Isto é, os meios de comunicação passam a ser significativos em assuntos onde o interesse estatal esteja presente, levando os pesquisadores a compreender os reais efeitos da mídia junto à política externa, à opinião pública e à própria realidade internacional. Na visão de Nye (2002; 2004), compreendese que a mídia como Soft Power ${ }^{10}$ somada ao Hard Power gera o Smart Power ${ }^{11}$, ou seja, as duas vertentes unidas e sinérgicas reverberam em um mecanismo de estruturação no sistema internacional.

De acordo com Gilboa (2001) e Valente (2007), a diplomacia pública é um mecanismo que traz novas regras e uma infinidade de implicações entre os governos e o grande público. Para tanto, a diplomacia, segundo o autor, é segregada em três postulados: a diplomacia pública, a diplomacia na mídia e a diplomacia pela mídia. Segundo Gilboa (2001), existe na atualidade um novo tipo de diplomacia que difere da pública, a chamada diplomacia midiática, cuja sociedade de informação age de modo que as influências de conglomerados comunicacionais atuem nas negociações internacionais. Assim, não se pode relegar, seja no âmbito pragmático da política externa quanto no seu estudo acadêmico, que a mídia consiste de fato em um importante ator da política externa.

\footnotetext{
${ }^{10}$ Joseph Nye cunhou o termo "poder brando" no final de 1980. Agora, é usado com frequência e muitas vezes de forma incorreta pelos líderes políticos, editorialistas e acadêmicosde todo o mundo. Soft power reside na capacidade de atrair e convencer, influenciando indiretamente o comportamento de outros Estados através dos meios culturais e ideológicos, conquistando seu objetivo através dos meios diplomáticos, culturais eideológicos.

${ }^{11}$ Smart Power (Poder inteligente) é um termo nas Relações Internacionais definido por Joseph Nye como sendo "a capacidade de combinar Hard e Soft power em uma estratégia vencedora". De acordo com Crocker, Hampson e Aall (2007), o smartpower "envolve o uso estratégico da diplomacia, persuasão, capacitação, projeção de poder e influência de modo que seja rentável e legitima como políticas sociais".
} 


\section{ESTUdOS DE RELAÇÕES INTERNACIONAIS, ANÁLISE DE POLÍTICA EXTERNA E MÍDIA NO BRASIL}

É importante dizer que os estudos de Relações Internacionais no Brasil são muito recentes, principalmente a título de graduação e de pós-graduação (stritu sensu). Como apontam Faria (2011) e Vigevani, Thomáz e Leite (2014), as primeiras pesquisas na área de Relações Internacionais, em termos mundiais, iniciaram suas atividades em 1919 no Departamento de Política Internacional na Universidade de Aberystwyth seguindo pela a London School of Economics (1928). Com relação ao Brasil, o primeiro curso de graduação iniciou suas atividades em 1974 na Universidade de Brasilia (UnB), tendo a criação de seu respectivo mestrado em 1984.

O segundo curso de graduação foi o da Universidade Católica de Brasilia (UCB), criando somente em 1995. Em 1987, o Instituto de Relações Internacionais (IRI) da Pontifícia Universidade Católica do Rio de Janeiro (PUCRJ) deu início ao curso de mestrado. Já os estudos de análise de política externa, como pontua Herz (2002), foram desenvolvidos a partir de meados da década de 50 do século XX, e havia naquela época uma busca pela compreensão de aspectos domésticos, como elementos decisórios, cognitivos individuais e coletivos. Nas palavras da autora, "a partir da década de 80 , observa-se uma tendência à superação dessa dicotomia, tendo diversos autores buscando trabalhar com ainteração entre processos políticos domésticos e internacionais" (Herz, 2002, p.11).

No que concerne à Análise de Política Externa como subárea das Relações Internacionais, é recente o desenvolvimento deste estudo, como apontam Faria (2011), Salomón e Pinheiro (2013), tendo sido um campo polêmico mesmo em países como EUA que apresentam hegemonia no campo das Relações Internacionais. Segundo Faria (2008), a APE apresenta especificidades em relação às Relações Internacionais mainstream, ou seja, apresenta metodologia, temática e teoria específica para o estudo de modo aprofundado.

Para Hudson (2007), Faria (2011), Salomón e Pinheiro (2013), a APE exige demarcações metodológicas e teóricas como mecanismos facilitadores. 
Nesse sentido, três elementos se destacam: (1) a explicação do processo decisório como multifatorial (examinar variáveis de mais de um nível de análise); (2) multinível e (3) a multi ou interdisciplinaridade. Na perspectiva de Salomón e Pinheiro (2013), quando se trata do estudo de análise de política externa no Brasil, o processo ainda encontra-se em consolidação, por exemplo, no campo instrumental teórico que, segundo as autoras, é cada vez mais usado na pesquisa acadêmica em vários cursos de graduação e programa de pósgraduação em Relações Internacionais.

$\mathrm{Na}$ atualidade, cada vez mais vem se constituindo a compreensão de que a política externa é política pública, ou seja, fatores domésticos interferem no externo e vice-versa, como também o entendimento de que existem outros atores (mídia, empresariado, movimentos sociais, ONGs) que exercem pressão e influência nos policymakers ou tomadores de decisão. Ainda de acordo com Faria (2011), Salomón e Pinheiro (2013) há no Brasil uma dificuldade por parte da área de discutir a influência da opinião pública na formulação e conteúdo da política externa brasileira, diferentemente dos EUA, onde a política externa americana é atrelada direta e indiretamente à opinião pública. Esse foi um dos motivos que nos fez trazer textos acadêmicos de cunho nacional e internacional para o programa do curso de extensão. Como afirma Badie (2010), "a opinião pública internacional torna-se um importante intruso nesse mundo de frios, que são condenados a acomodar-se e, alternadamente, a trapacear, manipular, mas também adaptar-se, às vezes ser flexível e, frequentemente, negociar" (Badie, 2010, p.214).

Por opinião pública compreendemos uma relação dinâmica entre a individualidade e a conjunção de fatores externos (como as condições sociais, econômicas e culturais). Fatores estes que transfiguram essa individualidade em grupos sociais. Opinião pública abarca a capacidade e a liberdade de mudar nossa opinião a qualquer momento a partir da relação que constituímos com o social e as dinâmicas que nele habitam. Isto se deve, por sua vez, ao acesso a maior ou menor conteúdo informacional que cada indivíduo em seu grupo social tenha, possibilitando refletir sobre um determinado tema e construir uma análise própria. Ou seja, a opinião pública é dinâmica e volátil. Dependendo do contexto, do tema a ser analisado, podemos identificar a opinião pública como propositiva 
e/ou reativa. Ela é propositiva quando propõe algo que acredite ser fundamental para uma determinada pauta, geralmente, essas pessoas que propõe algo são indivíduos que apresentam um maior nível de conhecimento e sabedoria. Já a opinião pública reativa é justamente o oposto, ou seja, ela reage seja através de críticas, análises que julga mais contundente.

No que concerne à opinião publicada, é tudo aquilo que vem oriundo dos meios de comunicação em diferentes plataformas tecnológicas escolhidas. Como já dizia Maffesoli (2010), a opinião publicada não deixa de ser opinião, mas pretende ser um saber, uma competência, até mesmo uma ciência. Para o autor, a opinião publicada continua a repetir exaustivamente algumas ideias convencionais, lugares comuns com base nos "bons sentimentos", sendo, portanto, muito convincente para a midiocracia que se acomoda de modo generalizado (Maffesoli, 2010, p.21).

É possível perceber que existe uma ausência dos estudos sobre mídia e relações internacionais, assim como de mídia e política externa. Muitos autores como Miyamoto (1999), Lessa (2005) e Vizentini (2005) apontam que tanto o ensino em nível de graduação como de pós-graduação na área de Relações Internacionais, cuja característica é a multidisciplinaridade, vieram oriundas da História, da Ciência Política, da Economia e do Direito, as quais, de algum modo, realizaram dentro dos seus programas de ensino aabertura para a área das Relações Internacionais.

É importante mencionar que instituições federais, como a Universidade do Estado da Paraíba (UEPB) ${ }^{12}$, vem desenvolvendo estudos atrelados a mídia e relações internacionais, e mídia e política externa em nível de graduação e pósgraduação (stritu senso). Em termos de pós-graduação, o Programa de Pós Graduação da Universidade do Estado do Rio de Janeiro (PPGRIUERJ) possui entre suas linhas de pesquisa uma disciplina chamada "Cultura e Relações

\footnotetext{
12 Grupos de pesquisa: A Construção Estratégica de Imagens do Brasil no Exterior: Comunicação Internacional e Política Externa na ótica da SECOM/Presidência da República (Prof ${ }^{\mathrm{a}}$. Dr ${ }^{\mathrm{a}}$. Silvia Garcia Nogueira); A construção estratégica de imagens do Brasil no exterior: comunicação internacional e políticaexterna na ótica da Secom/Presidência da República (PIBIC cota 2011-2012); Telesur, um estudo antropológico sobre as práticas e os ideais integracionistas da rede latino-americana de comunicação. Link:http://pos-graduacao.uepb.edu.br/ppgri/projetos-de-pesquisa/.
} 
Internacionais", que corrobora para a participação da mídia como ator tanto no âmbito da política externa quanto no segmento das relações internacionais.

Ao tratarmos do caso brasileiro, onde vigora o patrimonialismo midiático ${ }^{13}$ de modo assertivo, torna-se vital para estudantes e pesquisadores compreender a interface entre a mídia e as relações internacionais. Já dizia Raymundo Faoro (2001, p.500) que o Patrimonialismo consiste numa ordem burocrática cujo soberano se encontra sobreposto ao cidadão na qualidade de chefe para com o funcionário. Segundo o autor, o patrimonialismo é uma organização política básica marcada pela burocracia, porém a burocracia não pode ser vista no sentido moderno, como aparelhamento racional, mas como apropriação do cargo (Faoro, 2001, p.101). O patrimonialismo se molda às transições, às mudanças, em caráter flexivelmente estabilizador do modelo externo, concentrando no corpo estatal os mecanismos de intermediação, com suas manipulações financeiras, monopolistas, de concessão pública de atividade, de controle do crédito, de consumo, de produção privilegiada, numa gama que vai da gestão direta à regulamentação material da economia (Faoro, 2001, p.871).

Outra característica existente na mídia brasileira é o coronelismo eletrônico. De acordo com Santos (2008), o coronelismo eletrônico é o resultado da superposição de formas desenvolvidas do regime representativo a uma estrutura econômica e social inadequada. Não é, pois, mera sobrevivência do poder privado, mas sim, uma forma peculiar de manifestação do poder privado, ou seja, uma adaptação em virtude da qual os resíduos de nosso antigo e exorbitante poder privado têm conseguido coexistir com um regime político de extensa base representativa (Santos, 2008, p.224).

\footnotetext{
${ }^{13}$ É importante destacarmos que a América Latina é caracterizada pelo patrimonialismo e pelo clientelismo. Grande parte das emissoras surgiram das iniciativas do governo e das instituições vinculadas ao ap arato estatal marcados pela não independência editorial, financeira e submetidos a mecanismos de transparência e accontability. Segundo Esch; Del Bianco; Moreira (2012), os sistemas de TV e rádio tiveram origem a partir de duas lógicas de sistema público. Uma lógica que teve início em 1920/1930 cujo sistema público estava as sociado aos atores educativos e culturais. O segundo sistema público surgiu em 1940 cujo vínculo estava vinculado agenda governamental e estatal. A programação deste sistema é articulada a partir de programas culturais e musicais. Os noticiários estavam vinculados ao Estado, contudo ao longo do tempo o conteúdo passou a ser convertido como porta vozes do governo (Esch, Del Bianco e Moreira, 2012; Fontes, 2017, p.69).
} 
Nesse sentido, o coronelismo eletrônico é visto como um sistema organizacional da recente estrutura brasileira de comunicações, baseado na reciprocidade entre o poder nacional e o poder local tendo como configuração uma rede complexa de influências entre poder público e o poder privado dos chefes locais, proprietários dos meios de comunicação (Santos, 2008, p.224). Devemos ter atenção quando se menciona o conceito de coronelismo eletrônico tendo em vista que, por vezes, o conceito é tratado e/ou confundido com o antigo modelo de coronelismo da época da República Velha. O coronelismo dos dias atuais não subsiste no antigo sistema coronelista que envolvia os três níveis de governo. Assim sendo, não derruba governadores, não apresenta seu poder baseado na posse da terra e no controle da população.

Segundo Santos (2008, p.235), há uma ausência de expressividade econômica diante do crescimento de elites comerciais e industriais impedindo 0 coronel a valorizar seu poder político. A globalização, as novas tecnologias da comunicação e da informação e a democratização da sociedade podem desarticular e romper com o coronelismo, especialmente o eletrônico. É este o medo dos coronéis. Portanto, buscam alianças com empresários nacionais para receber conteúdos de qualidade oferecendo uma barreira aos grupos internacionais. Como nos evidencia Enrique Saraiva (2008), a liberdade de opinião pode atacar o sistema democrático ou defender o totalitarismo, ou o racismo e outras formas de discriminação social, sexual e religioso. Esse é, portanto, o poder político da mídia.

\section{INTERDISCIPLINARIDADE: LABORATÓRIO DE EXTENSÃO POLÍTICA EXTERNA, MÍDIA E OPINIÃO PÚBLICA.}

Como sinal da necessidade de buscar uma coesão entre a análise de política externa, principalmente no caso brasileiro, com a participação da mídia como um ator político importante, nasceu a proposta do Laboratório de Extensão "Política Externa, mídia e opinião pública". O conceito da interdisciplinaridade é de fundamental importância nessa proposta, pois se entende a interdisciplinaridade como sendo uma condição fundamental do ensino e pesquisa na sociedade contemporânea. 
A interdisciplinaridade parte de um ponto de cruzamento entre atividades (disciplinares e interdisciplinares) com lógicas diferentes. A dificuldade em fazer esta atividade, segundo Leis (2007), está na busca por um equilibrio entre a análise fragmentada e a síntese simplificadora, havendo, ainda segundo Leis (2007), uma espécie de "entrincheirem", ou seja, especialistas e subespecialistas tendem a compartilhar oconhecimento apenas entre seus pares. Contudo, a pesquisa social "é uma jornada colaborativa que une várias pessoas com diferentes combinações de ideias e evidências etambém de diferentes representações" (Ragin, 1994, p.164), ou seja, a pluralidade típicadas Ciências Sociais não a torna fragmentada ou entrincheirada, pois todas as maneiras de realização da pesquisa social têm o mesmo objetivo em prol da ciência social pela qual trabalham: prover interpretações sobre a realidade social na qual as pessoas vivem. Deacordo com Japiassu e Marcondes (2001):

(...) a interdisciplinaridade é um método de pesquisa e de ensino suscetível de fazer com que duas ou mais disciplinas interajam entre si, esta interação podendo ir da simples comunicação das ideias até a interação mútua dos conceitos, da epistemologia, da terminologia, da metodologia, dos procedimentos, dos dados e da organização da pesquisa. (...). (Japiassu; Marcondes, 2001, p.107).

Seguindo um raciocínio próximo, Teixeira (2007, p.59) compreende que "a interdisciplinaridade (...) pode significar uma estratégia de flexibilização e integração das disciplinas, nos domínios do ensino e da produção de conhecimentos novos, da pesquisa". Através da busca de ampliação de conhecimento, a interdisciplinaridade torna-se fundamental para desenvolver uma ciência capaz de unificar diversos pensamentos e permitir ao estudante uma visão ampliada dos fatos científicos e corriqueiros. Para demonstrar a relevância da interdisciplinaridade na atualidade, o autor apresenta o exemplo de um seminário de Interdisciplinaridade em 1970, realizado na Universidade de Nice, onde foi consenso entre os participantes, nas palavras dos mesmos, que "a crescente complexidade dos problemas enfrentados pelas sociedades modernas" e um fluxo acelerado de mudanças "exigem políticas científicas que fomentem o trabalho e a pesquisa interdisciplinar" (Teixeira, 2007, p.58).

Nesse sentido, um dos motivos da realização do curso de extensão foi integrar e ampliar o conhecimento dos alunos nas áreas de política externa, mídia e opinião pública, possibilitando que houvesse uma forma de pensar capaz 
de entender e analisar a realidade atual desses campos. Nota-se que essa questão fora anteriormente apresentada na década de 1970, o que demonstra a importância da interdisciplinaridade, tanto na questão da ampliação do conhecimento, como em decorrência dos fenômenos atuais de globalização e explosão de tecnologias comunicacionais.

Interdisciplinaridade, no entanto, não deve ser confundida com transdisciplinaridade. Segundo Pinto (2005), a transdisciplinaridade é uma tentativa articulada de enfrentar a complexidade gerada pelo grande número de novas disciplinas, que a cada momento são acrescentadas ao conjunto do saber contemporâneo. É importante afirmar que o Laboratório de Extensão "Política Externa, Mídia e Opinião Pública" passou por algumas dificuldades na sua gênese, por haver referências das duas áreas do conhecimento, ou seja, Relações Internacionais e Comunicação Social, com poucas referências bibliográficas produzidas nesse ponto de encontro entre ambos os campos. A diversidade de objetivos da pesquisa social e de maneiras de produzir representações da vida social de ambos os campos têm como resultado diferentes estudos que iluminam distintos aspectos da sociedade humana. Dessa maneira a interdisciplinaridade entre duas áreas auxilia na complementaridade dos conhecimentos e na produção de análises mais produtivas.

Ao longo dos cursos (4 semestres - 2015/1, 2015/2, 2016/1 e 2016/2), apresentaram-se voluntariamente 115 alunos(as) de diversas áreas e com graus de escolaridade variados (a disciplina não era obrigatória). Assim, foi necessária a articulação de diversas bases teóricas de conhecimentos oriundos das múltiplas formações dos alunos. Igualmente, havia certo desequilibrio de graus de conhecimento sobre as temáticas abordadas pelo curso entre os alunos, identificando-se desde aqueles que não tinham conhecimento algum, seja de uma área ou outra, até aqueles que tinham um conhecimento profícuo em uma das áreas que o Laboratório/Disciplina abordava. 


\section{Gráfico 1.}

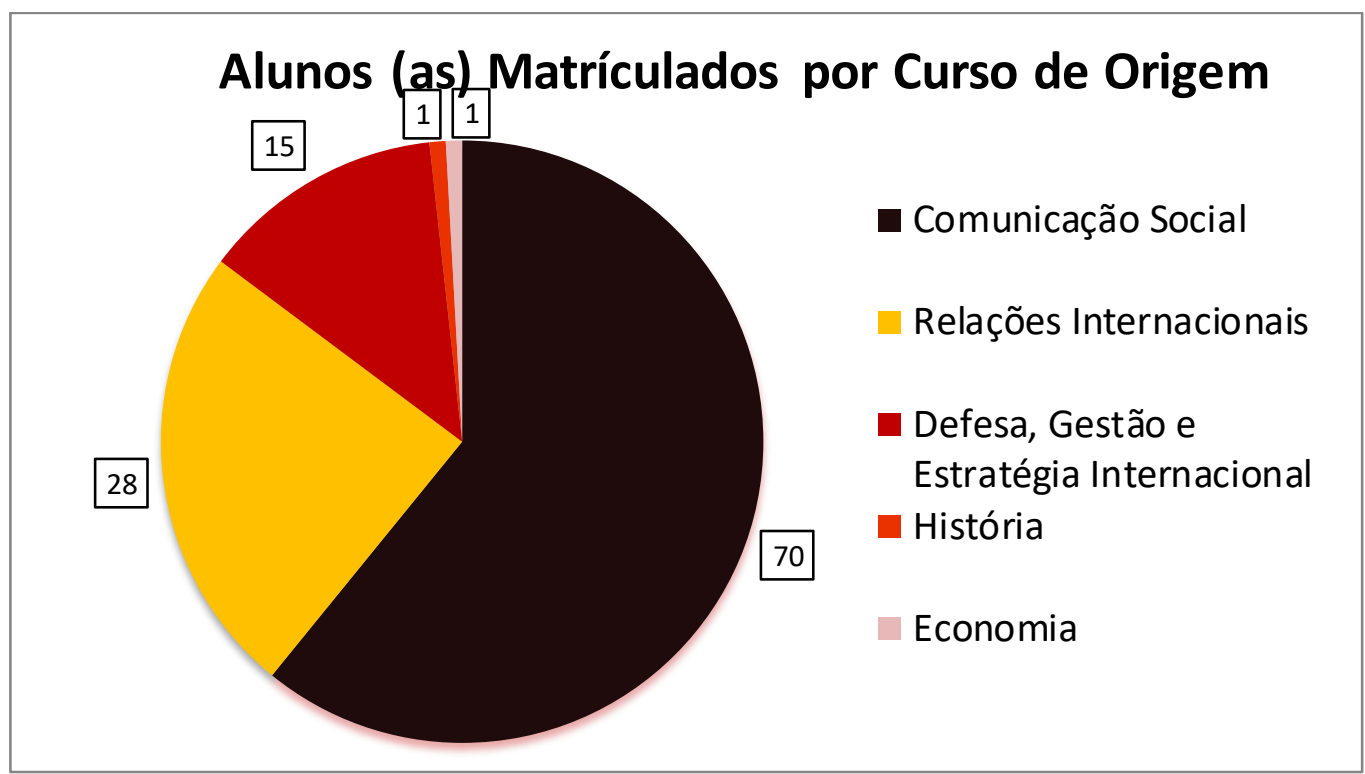

Fonte: Elaboração própria.

\section{Gráfico 2.}

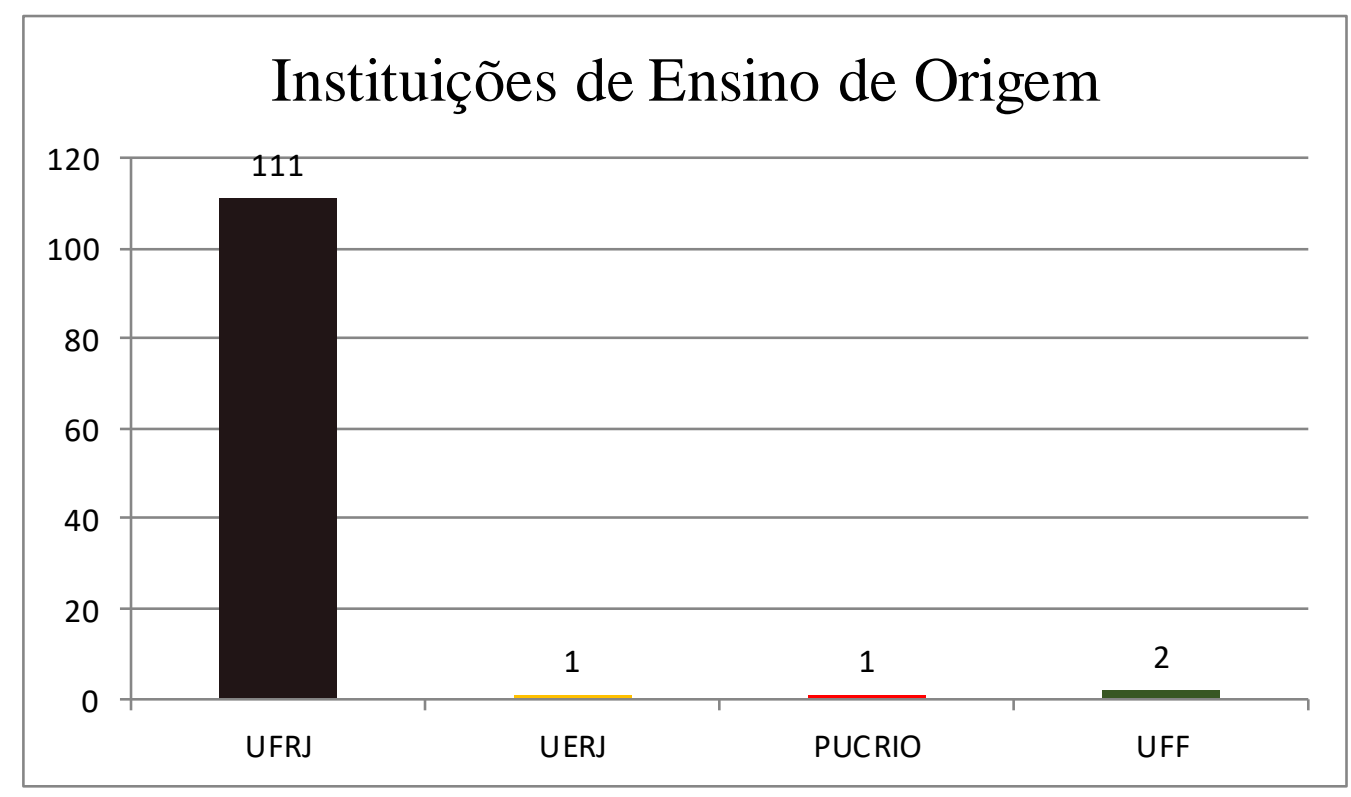

Fonte: Elaboração própria. 


\section{Gráfico 3.}

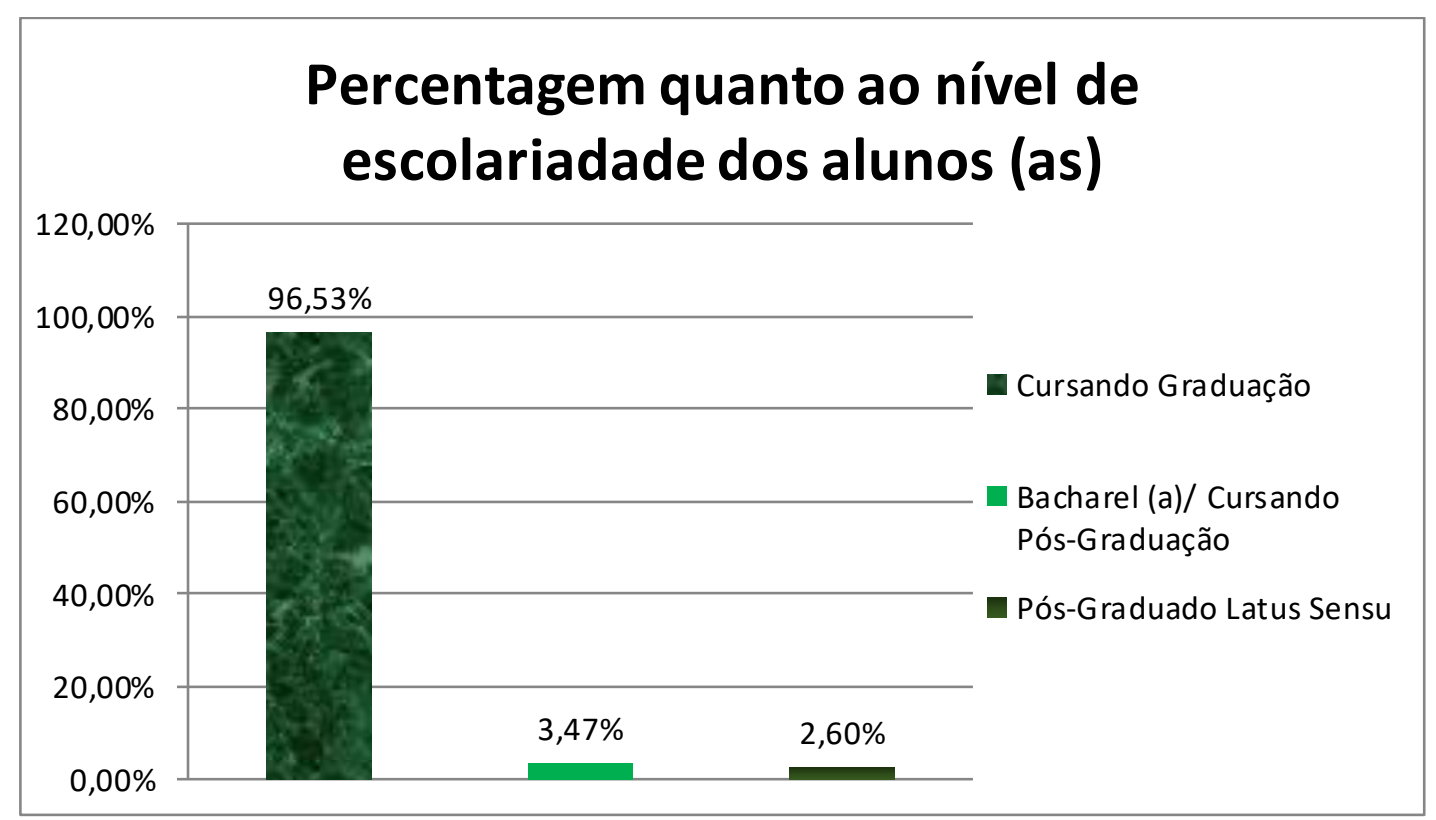

Fonte: Elaboração própria.

Logo, podemos observar que o perfil dos estudantes é misto, tendo em vista que $58 \%$ são mulheres, sendo uma turma equilibrada que abrange perfis de diversas áreas de conhecimento e níveis de ensino. Ainda assim, é importante registrar que todos os estudantes são oriundos de instituições no Estado do Rio de Janeiro, sendo elas públicas ou privadas. É importante ponderar que entendemos o conceito de extensão universitária, do mesmo modo que Serrano (2011), ou seja, a extensão como uma proposta que marca a história das universidades brasileiras, principalmente a das públicas, que passam por vários matizes e diretrizes conceituais. Da extensão em cursos à extensão através de serviços, à extensão assistencial, à extensão "redentora da função social da Universidade", à extensão como mão dupla entre universidade e sociedade, à extensão cidadã, podemos identificar uma ressignificação da extensão nas relações internas com os outros fazeres acadêmicos e na sua relação com a comunidade em que está inserida.

O Laboratório/Disciplina buscou compreender as mudanças observadas nas agendas da Política Externa Brasileira, pós-redemocratização, mais particularmente no que diz respeito aos atores domésticos e ao redimensionamento do papel do Ministério das Relações Exteriores. Nesse 
sentido, o projeto analisou, mais particularmente, a mídia como um novo ator da Política Externa Brasileira, entendendo seus repertórios, discursos e interesses, buscando para isso um arcabouço teórico com referências aos autores que estudam a relação entre a mídia e a Política Externa Brasileira (e a política externa em geral).

Do mesmo modo, o Laboratório/Disciplina propôs analisar as relações entre política externa e democracia tanto no plano internacional quanto no âmbito doméstico, com ênfase no debate normativo e na análise dos diferentes atores nas agendas, sendo o debate principal da disciplina o tratamento da política externa e o papel da mídia na cobertura de temas de política externa. Visando o papel da mídia nas agendas da política externa no Brasil e em perspectiva comparada de outros países, foi estimulado que os estudantes apresentassem análises sobre como a mídia poderia ser considerada um agente da política externa e sobre como os temas de política externa são tratados na imprensa (em diferentes plataformas).

As aulas ministradas pelos monitores, pós-graduandos de áreas correlacionadas à Análise de Política Externa, com a permanente participação e supervisão de uma professora responsável, pesquisadora da área da Comunicação Social, como guia para manter a perspectiva da mídia e da comunicação social em pauta, objetivaram os estudos entre as áreas da Política Internacional e da Comunicação Social. Os temas trabalhados foram: Política Externa como Política Pública, Novos Atores e Agenda: a mídia como novo ator; Mídia e Agenda; Opinião Pública e Política Externa; Diplomacia Pública, Midiática e Cultural; Mídia, e Integração Cultural; Globalização, Mídia e Relações Internacionais; Política Externa, Mídia e Análise de Conteúdo de Discurso e Análise de Discurso ${ }^{14}$.

As aulas ministradas contavam não apenas com arcabouço teórico, mas também com mecanismos de interação a partir do uso de recursos tecnológico. Durante as aulas foram utilizados filmes, documentários, reportagens a partir de telejornais tanto de amplitude nacional como internacional. Foi criado também,

14 Desde o início do laboratório/disciplina, as abordagens não foram restritas ao pensamento apenas positivista. Análises pós-positivistas a partir de literaturas construtivistas, pós-estruturais e/ou pósmodernas foram inseridas nos estudos de modo a democratizar as mais variadas análises. 
por meio do Facebook ${ }^{15}$, um espaço virtual do Laboratório/Disciplina como mecanismo de maior e melhor interação entre docentes e discentes. Por meio deste espaço foi possível construir junto aos alunos um corpus comum, em perspectiva de mão dupla, por meio de compartilhamento de informações incluindo fotos, vídeos, conteúdos jornalísticos, artigoscientíficos que envolveram temas das disciplinas.

Foram compartilhados 148 arquivos de conteúdos programáticos (textos complementares, textos analíticos e eventualmente suporte para o aluno com um maior interesse temático). Também foram compartilhadas 136 fotos referentes a palestras, eventos, simpósios, congressos relativos à proposta do Laboratório/Disciplina. Além disso, cerca de 800 matérias de jornais impressos, telejornais, web jornalismo, documentários, filmes, entrevistas, propagandas vinculadas no cotidiano que trouxessem de algum modo, temas que seriam tratados em sala de aula.

Do mesmo modo, o grupo, que recebeu o mesmo nome da disciplina, pôde ser utilizado como mecanismo de compartilhamento e envio do conteúdo programático da disciplina, aliado ao $\operatorname{Dropbox}^{16}$ e de um e-mail criado especialmente para a disciplina. Uma das primeiras mudanças importantes detectadas pela comunicação mediada por computador nas relações sociais é a transformação da noção de localidade geográfica das relações sociais, embora a internet não tenha sido a primeira responsável por esta transformação iniciada com o surgimento dos meios de transporte e de comunicação. O início da aldeia global é também o início da desterritorialização dos laços sociais (Recuero, 2009, p.135). Assim, a relação professor-aluno pode ser transportada da sala de aula para um ambiente virtual, possibilitando uma interação social digital e o prolongamento dos conteúdos trabalhados nas aulas.

\footnotetext{
15 A noção de redes se apresenta articulada às tecnologias da informação cujo debate vem sendo travado emvários campos do conhecimento. Segundo os autores Colonomos (1995) e Acioli (2007), a rede é um conjuntode relações sociais entre atores com pouca institucionalização, reunindo grupos numa espécie de as sociaçãocujos limites são variáveis e sujeitos a vários tipos de interpretações.

16 Dropbox é, sem dúvida alguma, uma das principais ferramentas da tecnologia de computação em nuvemou cloud computing. Criada pela empresa homônima, Dropbox Inc., tem sede no estado da Califórnia, em São Francisco, EUA. Tanto pode armazenar quanto compartilhar dados e arquivos. Esse armazenamento de dados é feito em computadores da própria empresa, que, a partir do momento em que faz a cópia, tornaos acessíveisa qualquer usuário que tenha conexão coma internet. Link:http://www.scriptbrasil.com.br/informatica/armazenamento/dropbox.html.
} 
O conteúdo ministrado foi abordado a partir de um rodízio entre os monitores com a coordenação da professora responsável, nas aulas oferecidas nas dependências da Escola de Comunicação da Universidade Federal do Rio de Janeiro (ECO/UFRJ), uma vez por semana, apresentando-se aproximadamente três horas de conteúdo programático por vez. Os alunos que se matricularam no curso, em sua maioria, foram motivados pela ausência de matérias que tratam da ligação entrea política externa e mídia em seus cursos. Juntamente com a ativa participação dos discentes ao longo do curso, através de debates e reflexões sobre os temas abordados, a identificação dessa lacuna temática corroborou para a importância desse curso interdisciplinar e também para as pesquisas a respeito da mídia e da opinião pública na política externa.

Por meio da vinculação entre as leituras bibliográficas, as quais constituíram o fundamento teórico da disciplina, com casos empíricos atuais e históricos, foi possível demonstrar a relevância da temática do curso e como a mesma ainda é um campo fértil para futuras pesquisas acadêmicas, principalmentenos tópicos referentes à mídia como ator, ao impacto da opinião pública, ao papel dos jornalistas e à comunicação social em geral como instrumento de formulação e fiscalizaçãoda política externa, brasileira ou de outros países.

Inicialmente inserida na grade curricular como um Laboratório experimental, a disciplina teve grande aceitação nos cursos de origem dos estudantes inscritos, levando a uma mudança de categoria de inserção e tornando-se uma disciplina eletiva, sob critérios e orientação da professora pesquisadora responsável. Destacamos também que o Laboratório/Disciplina serviu para alguns alunos como uma forma de mobilizá-los nas áreas acadêmicas de relações internacionais e mídia, promovendo a interdisciplinaridade na prática.

Alguns alunos, além de engajarem seus trabalhos de conclusão de curso em questões que envolvessem Mídia e Relações Internacionais, Política Externa e Mídia, também desenvolveram trabalhos sobre "Oriente Médio e Mídia", "Cinematografia e Criança-Soldado", Terrorismo e Internet. Outros alunos também se empenharam para criar, práticas que envolvessem a interdisciplinaridade entre mídia, política externa e opinião pública, 
desenvolvendo o Laboratório de Jogos de Simulação da ONU dentro e fora da Escola de Comunicação na UFRJ. Portanto, o interesse pela interdisciplinaridade ultrapassou as barreiras do Laboratório, transformando-se em objetos de pesquisas.

\begin{tabular}{|c|c|c|c|}
\hline \multicolumn{4}{|c|}{$\begin{array}{l}\text { Tabela 1: Alunos que seguiram com trabalhos e/ou áreas acadêmicas após o fim } \\
\text { do Laboratório/Disciplina }\end{array}$} \\
\hline Área de Origem & $\begin{array}{l}\text { Trabalhos } \\
\text { Acadêmicos }\end{array}$ & $\begin{array}{ll}\text { Trabalhos } & \text { de } \\
\text { Conclusão } & \text { de } \\
\text { Curso } & \end{array}$ & $\begin{array}{l}\text { Ingresso na Pós- } \\
\text { Graduação } \\
\text { Sensu e Lato-Sensu) }\end{array}$ \\
\hline Comunicação & 4 & 1 & $4^{2}$ \\
\hline $\begin{array}{l}\text { Relações } \\
\text { Internacionais }\end{array}$ & 0 & 4 & 2 \\
\hline $\begin{array}{l}\text { Defesa Gestão e } \\
\text { Estratégia } \\
\text { Internacional }\end{array}$ & 1 & 2 & 0 \\
\hline Economia & 2 & 0 & 1 \\
\hline
\end{tabular}

1 Alunos (as) que ou concluíram a Pós Graduação (Especialização ou Mestrado) ou que passaram em seleção.

2 Um aluno foi contabilizado de forma duplicada, visto que o trabalho abordou a interdisciplinaridade proposta na disciplina e foi aprovado no Mestrado.

Fonte: Elaboração própria.

Uma parte também destes alunos conseguiram publicar seus respectivos artigos produzidos em revistas acadêmicas do campo das Relações Internacionais. Também destacamos que alguns destes alunos participaram de seminários interdisciplinares no âmbito da UFRJ e nos encontros nacionais da área de Comunicação, das Relações Internacionais e da Ciência Política (Intercom, ABRI, Politicom, ABCP, FBCP). Além disso, informamos também, que foi aberto junto ao CNPq, um laboratório interdisciplinar (Laboratório de Estudos sobre Mídia e Relações Internacionais - LEMRI) com a participação de estudantes de graduação, pós-graduação e doutores (as) de diversas instituições/unidades (UFRJ, UERJ, UNIRIO, PUCRIO) e de diversas áreas (Comunicação Social, Relações Internacionais, Ciência Política, Ciências Sociais e Economia Política Internacional) reafirmando o trabalho com o ensino, a pesquisa e a extensão. 
O Laboratório/Disciplina também proporcionou que outras temáticas, antes não exploradas, pudessem ser ampliadas. Em 2017, uma nova disciplina (eletiva) surgiu cujo enfoque deu-se no campo dos estudos midiáticos, relações internacionais e questões humanitárias. Análises pós-estruturais, construtivistas, pós-coloniais e estudos sobre gênero (Teoria feminista e Teoria Queer) novamente foram mobilizadas nos debates. Estudos sobre fotografia humanitária, virada estética, cinematografia puderam ser discutidos em sala de aula. Estudantes de publicidade e propaganda, cinema e produção editorial passaram a compor com maior número de estudantes interessados na interdisciplinaridade. Em média 80 alunos se inscreveram, sendo a maioria do sexo feminino.

\section{CONSIDERAÇÕES FINAIS}

O objetivo deste artigo foi provocar reflexões a partir da compreensão da política externa como política pública e consolidar a interdisciplinaridade existente entre Comunicação Social e Relações Internacionais como uma área efetiva e importante de pesquisa. Nesse sentido, a mídia é vista como um dos atores que imprimem, através dos seus veículos de comunicação, desde as plataformas impressas às mídias eletrônicas e digitais, a partir das notícias sobre a conjuntura internacional e a política externa, uma pressão na agenda da política externa e internacional brasileira. Não obstante, o artigo mostrou, a partir de reflexões bibliográficas de recentes estudos e da difusão dos conteúdos atrelados às relações internacionais no Brasil, a ausência do tema da mídia, progressivamente complexo, na formação dos cursos de graduação e pósgraduação em relações internacionais.

Quando tal relação aparece, ela se faz presente a partir de disciplinas eletivas, também chamadas de optativas. É importante ponderar que o artigo também buscou, a partir da observação participante do lecionamento do curso, retratar a interdisciplinaridade entre as relações internacionais, a subárea análise de política externa, a mídia (em diversas variáveis de atuação) e a opinião pública. Nesse sentido, o curso de extensão "Política Externa, Mídia e Opinião Pública", criado em fevereiro de 2015, propiciou não apenas um mecanismo de 
debate, mas também um ato de reflexão sobre a relação destas duas áreas, que cada vez mais apresentam uma tendência de conexão, além da existência do interesse pela temática entre os alunos que vivem as influências e as consequências dos processos políticos tanto na academia quanto em suas experiências comunicacionais diárias.

O que buscamos neste artigo é começar a destacar não apenas a partir dos estudos e de reflexões teóricas sobre a relação entre mídia e relações internacionais, mas também enfatizar a importância destas áreas. É evidente que não pretendemos esgotar este tema, pelo contrário, este é apenas um passo inicial objetivando registrar e aprofundar, em longo prazo, os estudos sobre a interdisciplinaridade das duas áreas, identificando bibliografia, gráficos, tabelas e pesquisas em geral.

Sobretudo a partir das últimas décadas do século $X X$, onde se observou o vertiginoso desenvolvimento tecnológico dos meios de comunicação, marcado pelo surgimento de novas mídias, como a internet, o celular e o IPTV, e, por conseguinte, pela transformação do status e do consumo da informação, as novas estratégias passaram a ser organizadas para a sobrevivência do ameaçado controle do establishementsobre a informação. Da mesma maneira, para a sobrevivência dos conglomerados que constituem a tradicional imprensa escrita e televisiva, eles passaram a concorrer com uma infinidade de blogs, sites, redes de sociabilidades e IPTVs que reconfiguraram a produção e 0 consumo da informação.

Como previu McLuhan (1971), a revolução tecnológica dos meios de comunicação, iniciada com a televisão, transformou o mundo em uma "aldeia global". Deste modo, o público, cada vez mais amplo, busca se inteirar sobre as questões internacionais, antes circunscritas aos círculos dos especialistas do mundo político, econômico e dos governos. É a "cultura da mídia e o triunfo do espetáculo" (Kellner apud Lessa 2011) que transforma eventos esportivos, fatos diversos ou fenômenos políticos marcantes em "mega espetáculos políticos" agora mais do que nunca abertos ao cidadão tecnologicamente empoderado, que se faz presente na "Esfera Pública" por meio digital. Daí, a justificativa de se entender a importância política exercida pelos conglomerados comunicacionais nas relações internacionais. 


\section{REFERÊNCIAS BIBLIOGRÁFICAS}

Acioli, Sônia. "Redes Sociais e Teoria Social: revendo os fundamentos do conceito". Revista Informação \& Informação, vol.12, número especial(2007): 8-19.

Badie, Betrand. "A opinião à conquista do internacional". In Relações Internacionais: perspectivas francesas, organizado por Carlos R. S. Milani, Salvador: EDUFBA, 2010. Bull, Hedley. Sociedade Anárquica. Brasília: UNB, 1977.

Boellstorff, T. 2011. Placing the Virtual Body: Avatar, Chora, Cypherg. In A Companion to the Anthropology of the Body and Embodiment, ed. F. E. Mascia-Lees, 504-20. New York: Wiley-Blackwell.

Castells, Manoel. "Redes de indignação e esperança. Movimentos sociais na era da internet." Rio de Janeiro: Ed Zahar, 2013.

Cheibub, Zairo (1985). "Diplomacia e Construção Institucional: O Itamaraty em umaperspectiva histórica". Dados, vol. 28, n. 1 (1985): 113-131.

Colonomos, Ariel. "Emergence d'un objet et perspectives internacionalistes". In Sociologie des réseauxtransnationaux: communautés, enterprises et individus - lien social et système international. Paris: Editions L'Harmattan, 1995.

Crocker, Chester A., Hampson, Fen Osler e Aall, Pamela R. Leashing the Dogs of War: Conflict Management in a Divided World. Washington, D.C.: United States Institute of Peace Press, 2007.

Esch, Carlos Eduardo, Del Bianco, Nelia Rodrigues e Moreira, Sonia Virgínia. "Radiodifusão Pública: um desafio conceitual na América Latina". Revista FSA, v. 10, no 4, (2013): 67-86.

Faoro, Raymundo. Os Donos do Poder: A Formação do Patronato político brasileiro. Rio de Janeiro: Editora Globo, 2001.

Faria, Carlos Aurélio Pimenta de. "Opinião pública e política externa: insulamento, politização e reforma na produção da política exterior do Brasil". Revista Brasileira de Política Internacional, no51 (2008): 80-97.

Faria, Carlos Aurélio Pimenta de. "O ensino e a pesquisa sobre política externa nocampo das Relações Internacionais do Brasil". Trabalho apresentado no III Encontro da Associação Brasileira de Relações Internacionais (ABRI), São Paulo: USP, 20 a 22 de julhode 2011.

Fontes, Pablo. Mídia e Relações Internacionais: A criação e existência da TeleSUR durante a Era Chávez (1999-2013). Dissertação de Mestrado em Relações Internacionais pelo Programa de Pós-Graduação em Relações Internacionais da Universidade do Estado do Rio de Janeiro (PPGRIUERJ), 2017.

Formiga, Fábio de Oliveira Nobrec. "A Evolução da Hipótese de Agenda-Setting". Brasília: Programa de Pós-Graduação da Faculdade de Comunicação da Universidade de Brasília (UNB), 2006.

Gilboa, Eytan. "Diplomacy in the media age. Three models of uses and effects". Diplomacy \& Statecraft, vol.12, no.2 (2001): 1-28.

Hermann, Margaret G.; Hermann, Charles F. "Who Makes Foreign Policy and How: an Empirical Inquiry”. International Studies Quarterly, vol. 33, n44, 1989.

Herz, Mônica. "O crescimento da Área de Relações Internacionais no Brasil". Revista Contexto Internacional, PUC-RIO, vol.24, №1 (2002): 7-40.

Hill, Christopher. The Changing Politics of Foreign Policy. Nova York: PalgraveMacmillan, 2003.

Horst, Heather A; Miller, Daniel. Digital Anthropology. London: BERG, 2012.

Hudson, Valerie. "Foreign Policy Analysis: Actor - Specific Theory and theGround of International Relations". Foreign Policy Analysis, vol. 1, issues 1 (2005): 1-30.

Japiassu, Hilton e Marcondes, Danilo. Dicionário Básico de Filosofia. Rio de Janeiro: Jorge Zahar Editor, 2001. 
Leis, Héctor Ricardo (2008). "Sobre o Conceito de Interdisciplinaridade". Cadernos de pesquisa interdisciplinar em ciências humanas, no 73 (2008): 2-23.

Lessa, Antônio Carlos. "O ensino de relações internacionais no Brasil". In O Crescimento das Relações Internacionais no Brasil, organizado por Amado Cervo e José Flávio Sombra Saraiva. Brasília: Instituto Brasileiro de Relações Internacionais (IBRI), 2005.

Lessa, Mônica Leite. "Bens e Serviços Culturais: O Lugar do Brasil na Cena Internacional (2001-2006)". In A quarta dimensão das relações internacionais: a dimensão cultural, organizado por Hugo Rogelio Suppo e Mônica Leite Lessa. Rio de Janeiro: Editora Contra Capa, 2012.

Lévy, Pierre. A Máquina Universo. Tradução Bruno Charles Magne. Porto Alegre: ArtMed, 1998.

Lemos, André (coord.). Cidade, tecnologias e interfaces. Análise de interfaces de portais governamentais brasileiros. Uma proposta metodológica. Revista Fronteiras. Estudos Midiáticos. Vol. VI, no-2 p.117-136. São Leopoldo, 2004.

Lowi, Theodore. "Making Democracy Safe for the World: National Politics and Foreign Policy". In Domestic Sources of Foreign Policy, editado por James Rosenau, 295-332, Nova York: Free Press, 1966.

Maffesoli, Michel. Saturação. São Paulo: lluminuras: Itaú Cultural, 2010.

Mcluhan, Marshall e Fiore, Quentin. Guerra e paz na aldeia global. Rio de Janeiro: Record, 1971.

Matsuda, Toshito Celso. Governo eletrônico, a reforma democrática do Estado-Nação: a prefeitura da cidade de São Paulo: ECA-USP, 2006, Tese de doutorado.

Milani, Carlos R. S e Pinheiro, Letícia. "Política Externa Brasileira: Os Desafios de sua Caracterização como Política Pública”. Contexto Internacional, vol. 35, №1 (2013): 1141.

Milner, Helen V. Interests, Institutions and Information, Domestic Politics and International Relations. Princeton: Princeton University Press, 1997.

Miyamoto, Shiguenoli (1999). "O estudo de relações internacionais no Brasil: O estado da arte". Revista de Sociologia e Política, n 12, (1999): 83-98.

Nye, Joseph S. Power in the global information age. New York: Routledge, 2014.

Oliveira, Rafael de. A mídia como ator emergente das relações internacionais: seu protagonismo no uso do soft Power frente aos desafios das mudanças climáticas. Santa Catarina: Tese de Doutorado em Direito, 2010.

Pinheiro, Letícia (2000). "Traídos pelo desejo: um ensaio sobre a teoria e a prática da Política Externa Brasileira contemporânea". Contexto Internacional, vol.22, no 2 (2000): 305-335.

Pinheiro, Letícia e Milani, Carlos R. S. (org.). Política externa brasileira: as práticas da política e a política das práticas. Rio de Janeiro: Fundação Getúlio Vargas, 2012.

Pinto, Paulo Roberto Margutti. "A lógica contemporânea e a transdisciplinaridade". Conhecimento e transdisciplinaridade II, organizado por Ivan Domingues, 137-168. Belo Horizonte: UFMG, 2005.

Postil, John. Digital Politics and Political Engagement. In Horst, Heather A; Miller, Daniel. Digital Anthropology. London: BERG, 2012.

Putnam, Robert D. "Diplomacia e Política Doméstica: a lógica dos jogos de doisníveis". Revista Sociologia Política, Curitiba, vol.18, no 36, (2010): 147-174.

Ragin, Charles C. Constructing Social Research. Thousand Oaks: Pine Forge Press, 1994.

Recuero, Raquel. Redes Sociais na Internet. Porto Alegre: Editora Sulina, 2009.

Salomón, Mónica, Pinheiro, Letícia. (2013). "Análise de Política Externa e Política Externa Brasileira: trajetória, desafios e possibilidades de um campo de estudos". Revista Brasileira de Política Internacional, vol. 56, no 1(2013): 40-59.

Santos, Suzy dos. "Os prazos de validade dos coronelismos: transição no coronelismo e no coronelismo eletrônico". In Democracia e Regulação: dos meios de comunicação 
de massa, organizado por Enrique Saraiva, Paulo Emílio Matos Martins e Octavio Penna Pieranti. Rio de Janeiro: FGV, 2008.

Serrano, Rossana Maria Souto Maior. Conceitos de extensão universitária: umdiálogo com Paulo Freire. S/A. 2011.

Teixeira, Evilázio F. B. "Emergência da Inter e da Transdisciplinaridade na Universidade". In Inovação e Interdisciplinaridade na universidade, organizado por Jorge L.N. Audy e Marília Costa Morosini, 58-80. Porto Alegre: EDIPUCRS, 2007.

Traquina, Nelson. Teoria do Jornalismo: Porque as notícias são o que são. Volume I $\left(1^{\circ}\right.$ edição) Insular, 2005.

Valente, Leonardo. Política Externa na Era da Informação. Rio de Janeiro: Editora Revan/UFF, 2007.

Vigevani, Túlio, Thomaz, Lais Forti e Leite, Lucas Batista. "As Relações Internacionais no Brasil: notas sobre o início de sua institucionalização". Revista InterRelações, ano 14, n40 (2014): 5-11.

Vizentini, Paulo Fagundes. "A evolução da produção intelectual e dos estudos acadêmicos de relações internacionais no Brasil". In O Crescimento das Relações Internacionais no Brasil, organizado por Amado Cervo e José Flávio Sombra Saraiva. Brasília: Instituto Brasileiro de Relações Internacionais (IBRI), 2005.

Waltz, Kenneth N. (1996). "International Politics is not Foreign Policy". Security Studies, vol. 6, no1, (1996): 54-57.

Wasik, B. And Then There's This: How Stories Live and Die in Viral Culture. New York: Viking Press, 2009.

Recebido em 03 de abril de 2017. Aprovado em 21 de julho de 2017. 